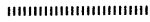

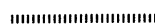 \\ アルカリ処理による石炭中の鉱物質の 脱離挙動に関する研究
}

\author{
-1986. 8. 19 受理一
}

東北大学 大塚 康夫, 王 征宇, 富田 彰

\section{1. 緒 言}

石炭中に多量の鉱物質が含まれることは，燃料とし て石炭を使用する際の大きな欠点となっている。輸送， 貯蔵に際しては，不必要なコストを付け加えることに なり，転換工程においては，灰分のハンドリングが困 難な問題をもたらす。また，黄鉄鉱からの硫黄分排出， 廃棄灰分からの有害物質の浸出など環境面でも多くの 問題をひきおこすことになる1２）。したがって，石炭 を予備処理して，鉱物質を除去しておくことは非常に 有意義である。石炭中の前処理によるクリーニングに ついては，これまでも数多くの研究が行われ，とくに 米国を中心に硫黄分除去をおもな目的とする研究が強 力に推進された ${ }^{3)}$ 。その結果によると, 重液分離法, 油 凝集法などの物理的処理法では，大部分の黄鉄鉱を除 去することはできるが，有機硫黄の除去は本質的に困 難であること，アルカリ処理などの化学的方法ではあ る程度の有機硫黄も除去できるが完全に除去すること はできないこと，などが明らかになってきた4) 6)。そ こで，われわれは，完全な硫黄分除去を目的とせず， むしろ鉱物質の完全除去を目的とするプロセスの方が 現実に利用できる可能性があるのではないかと考えた。 もちろん, 硫黄分の除去率は高ければ高いほど望まし いのは言うまでもない。前報では, Miller Blend, Wandoanの 2 種の石炭を用いて, 穏和なアルカリ処 理による脱灰の最適条件の検討を行い, ほぼ満足でき る結果を得た7)。脱硫率はかなり低かったが，これら の石炭中に含まれる硫黄分の絶対量が少ないため，十 分な検討をするには至らなかった。本報告では，新た に三池炭とIllinois No.6炭を用いて，鉱物質除去率な ぞが石炭の種類によってどのように異なるかを明らか にすることを試みた。また，処理前後の石炭灰の形態 非水溶液化学研究所 仙台市片平 $2-1-1$
や金属元素の組成などを明らかにすることにより，脱 灰挙動の詳細を把握することに重点を置いた。また， この両石炭は, 硫黄分の含有量が比較的多いので, 脱 硫挙動についても若干検討を加えた。

\section{2. 実験}

\section{1 石炭試料}

用いた石炭試料の工業分析，元素分析結果をTable 1に示す。今後, 石炭名はこの表に示す略号を用いる ことにする。灰分分析は, アルカリ処理後の灰分分析 結果とともにTable 2に示す。いずれの石炭でも $\mathrm{Si}$, Al成分が多いのであるが, $\mathrm{Ca}, \mathrm{Mg}$ 成分はMK炭とWD 炭に比較的多く, 本報で主として用いたMK炭とIL炭 には他の石炭に比べてFe成分が多い。硫黄の全分析 は炭素·硫黄分析計 (堀場製作所, EMIA-1200)によ り，Pyrite硫黄の形態別分析は, ASTM D 2492の方法 を改良したGladfelterら ${ }^{8)}$ の方法に準拠してFe分を $\mathrm{HCl}, \mathrm{HNO}_{3}$ で順次抽出することにより求めた。 $\mathrm{MK}$ 炭とIL炭については全硫黄のうち,かなりの部分が Pyrite硫黄であることがわかる。これはこの両石炭に $\mathrm{Fe}$ 分が比較的多く含まれることと関係している。形 態別硫黄分析の結果から推定されるPyriteの形のFe分 はMK炭の場合で全Fe分の約 7 割，IL炭の場合で約 5 割であった。なお，今回は有機硫黄，硫酸塩硫黄の 形態別分析は行っていないが，IL，MK炭ともに硫酸 塩硫黄は少ないことが知られているので，残りのほと んどが有機硫黄と考えてさしつかえない。

\section{2 脱灰および脱灰炭の分析}

詳細な実験方法は前報 7 にに記してあるので省略し， 要点のみを記すことにする。32-60メッシュの石炭約 $5 \mathrm{~g}$ を加圧処理の可能なテフロン製ルッボに所定濃度 の $\mathrm{NaOH}$ 水溶液とともに入れ, 所定温度で処理する。 処理炭は $\mathrm{HCl}$ 水溶液，およびイオン交換水で十分洗浄 
Table 1 Proximate and ultimate analysis

\begin{tabular}{|c|c|c|c|c|c|c|c|c|c|c|c|}
\hline \multirow{2}{*}{ Coal } & \multirow{2}{*}{ Code } & \multicolumn{3}{|c|}{$\begin{array}{c}\text { Proximate analysis } \\
(\%, \mathrm{db})\end{array}$} & \multicolumn{5}{|c|}{$\begin{array}{l}\text { Ultimate analysis } \\
(\%, \text { daf })\end{array}$} & \multicolumn{2}{|c|}{$\begin{array}{l}\text { S analysis } \\
(\%, \mathrm{db})\end{array}$} \\
\hline & & Ash & VM & $\mathrm{FC}$ & $\mathrm{C}$ & $\mathrm{H}$ & $\mathrm{N}$ & $\mathrm{S}$ & $\mathrm{O}$ & Total & Pyr. \\
\hline Wandoan & WD & 7. 0 & 43.4 & 49. 6 & 76.6 & 5.8 & 1.3 & 0.2 & 16. 1 & 0.2 & 0.03 \\
\hline Illinois No. 6 & IL & 10.8 & 39.0 & 50.2 & 79.7 & 5.5 & 1.3 & 3. 6 & 9.9 & 3.2 & 0.93 \\
\hline Miller Blend & MB & 15.5 & 32.6 & 51.9 & 81.3 & 5.3 & 2.1 & 1.5 & 9.8 & 1.3 & 0.05 \\
\hline Miike & MK & 21.2 & 37.4 & 41.4 & 83.6 & 6.6 & 1.2 & 3. 7 & 4. 9 & 2. 9 & 1.3 \\
\hline
\end{tabular}

Table 2 Ash analysis

\begin{tabular}{|c|c|c|c|c|c|c|c|c|c|}
\hline \multirow{2}{*}{\multicolumn{2}{|c|}{ Coal }} & \multicolumn{8}{|c|}{ Ash composition (\%) } \\
\hline & & \multirow{2}{*}{$\begin{array}{c}\mathrm{SiO}_{2} \\
52\end{array}$} & \multirow{2}{*}{$\begin{array}{c}\mathrm{Al}_{2} \mathrm{O}_{3} \\
26\end{array}$} & \multirow{2}{*}{$\frac{\mathrm{Fe}_{2} \mathrm{O}_{3}}{3}$} & \multirow{2}{*}{$\frac{\mathrm{CaSO}_{4}}{18}$} & \multirow{2}{*}{$\begin{array}{c}\mathrm{MgO} \\
3\end{array}$} & \multirow{2}{*}{$\frac{\mathrm{Na}_{2} \mathrm{SO}_{4}}{4}$} & \multirow{2}{*}{$\begin{array}{c}\mathrm{K}_{2} \mathrm{O} \\
0\end{array}$} & \multirow{2}{*}{$\begin{array}{c}\text { Total } \\
106\end{array}$} \\
\hline WD & $\mathrm{RC}^{\mathrm{a}}$ & & & & & & & & \\
\hline & $\mathrm{TC}^{\mathrm{b}}$ & 73 & 13 & 2 & 4 & 1 & 2 & 1 & 97 \\
\hline \multirow[t]{2}{*}{ IL } & $\mathrm{RC}$ & 49 & 17 & 17 & 11 & 1 & 3 & 2 & 101 \\
\hline & $\mathrm{TC}$ & 34 & 5 & 49 & 2 & 1 & 10 & 2 & 103 \\
\hline \multirow[t]{2}{*}{$\mathrm{MB}$} & $\mathrm{RC}$ & 70 & 20 & 1 & 2 & 1 & 0 & 1 & 96 \\
\hline & $\mathrm{TC}$ & 58 & 12 & 5 & 6 & 2 & 16 & 1 & 100 \\
\hline \multirow[t]{2}{*}{ MK } & $\mathrm{RC}$ & 49 & 17 & 11 & 18 & 1 & 9 & 2 & 106 \\
\hline & $\mathrm{TC}$ & 34 & 10 & 13 & 17 & 2 & 31 & 0 & 107 \\
\hline
\end{tabular}

${ }^{\mathrm{a}} \mathrm{RC}, \mathrm{Raw}$ coal

${ }^{b}$ TC, Treated coal (Ash reduction was around $80 \%$ for all the coals)

する。脱灰率は次の式により定義する。

脱灰率 $(\%)=$

$\left[1-\frac{\text { 処理炭中の灰分含有量 }(\%, \mathrm{db})}{\text { 原炭中の灰分含有量 }(\%, \mathrm{db})}\right] \times 100$

また, 石炭回収率は処理炭と原炭のdafベースでの重 量比から算出した。

処理前後の石炭の灰分組成は, $810^{\circ} \mathrm{C}$ で調製した高 温灰 (HTA) とプラズマ死化炉を用いて $150{ }^{\circ} \mathrm{C}$ 程度の低 温で調製した低温灰(LTA)の双方について調べた。 灰を $\mathrm{HCl}-\mathrm{HNO}_{3}-\mathrm{HF}$ 溶液, あるい: $\mathrm{HClO}_{4}-\mathrm{HF}$ 溶液で 溶解したのち, $\mathrm{Si}, \mathrm{Al}, \mathrm{Fe}, \mathrm{Ca}, \mathrm{Mg}, \mathrm{Na}, \mathrm{K}$ の各元 素含有量を原子吸光法により求めた。灰分の化学形態 は $\mathrm{Cu}-\mathrm{K} \alpha$ 線を用いたX線回折法によって決定した。

石炭発熱量の測定はJIS M 8812 の方法に準拠して 行った。

\section{3. 結果と考察}

3.1 石炭による脱灰率の差異

Table 3には, 4 種の石炭を種々の条件下で $\mathrm{NaOH}$ 処
理したときの処理炭中の灰分含有量と式 (1)で定義し た脱死率を示す。石炭は左から右へ原炭中の灰分量の 増える順序に並べてある。アルカリ濃度, 反応温度, 反応時間によって脱灰率が変化する様子は前報と同様 である。また，表から明らかなように，原炭中の灰分 の少ない石炭采ど脱灰率は大きく, 灰分の絶対量も少 なくなっている。灰分含有量の少ないWD，IL炭の場 合は，条件を厳しくすれば，90\%以上の脱灰率，1\% 以下の灰分の絶対量を得ることは容易であるのに対し て, MK炭では $80 \%$ 以上の脱灰率，1\%以下の灰分含 有量を達成することは本条件下では困難である。しか ᄂ, 強力な擋拌 ${ }^{7)}$, より高い反応温度 ${ }^{9)}$-11), 酸素の加圧 12)13)，溶融塩の利用 ${ }^{14)}$ 15) などのさらに厳しい条件下で 行えば，脱灰率を上げることは可能である。上に述べ たよらな石炭の種類による差異が, 単に原炭中の灰分 量によるのか，灰分組成によるのかについては以下に 述べる。

3.2 アルカリ処理による死分組成の変化 
Table 3 Effect of coal type on the ash reduction upon alkali treatment

\begin{tabular}{|c|c|c|c|c|c|c|}
\hline \multirow{2}{*}{$\begin{array}{l}\mathrm{NaOH} \text { conc. } \\
\text { (N) }\end{array}$} & \multirow{2}{*}{$\begin{array}{l}\text { Temp. } \\
\text { (K) }\end{array}$} & \multirow{2}{*}{$\begin{array}{l}\text { Time } \\
(\min )\end{array}$} & \multicolumn{4}{|c|}{ Ash in treated coal $(\%$, dry $)[$ Ash reduction $(\%)]$} \\
\hline & & & WD & IL & $\mathrm{MB}$ & MK \\
\hline \multirow[t]{3}{*}{4} & 430 & 60 & $2.6[63]$ & $6.6[39]$ & $12.8[17]$ & $15.4[27]$ \\
\hline & 430 & 150 & - & $3.4[68]$ & $6.0[61]$ & - \\
\hline & 460 & 150 & - & $1.9[82]$ & $3.0[81]$ & $8.9[58]$ \\
\hline \multirow[t]{3}{*}{10} & 430 & 60 & 1. $6[78]$ & - & $10.5[32]$ & - \\
\hline & 460 & 150 & $0.9[87]^{\mathrm{a}}$ & - & $2.7[82]$ & $5.9[72]$ \\
\hline & 460 & 300 & - & $0.6[95]$ & $2.1[86]$ & $4.6[78]$ \\
\hline
\end{tabular}

${ }^{a}$ Reaction time, $60 \mathrm{~min}$.

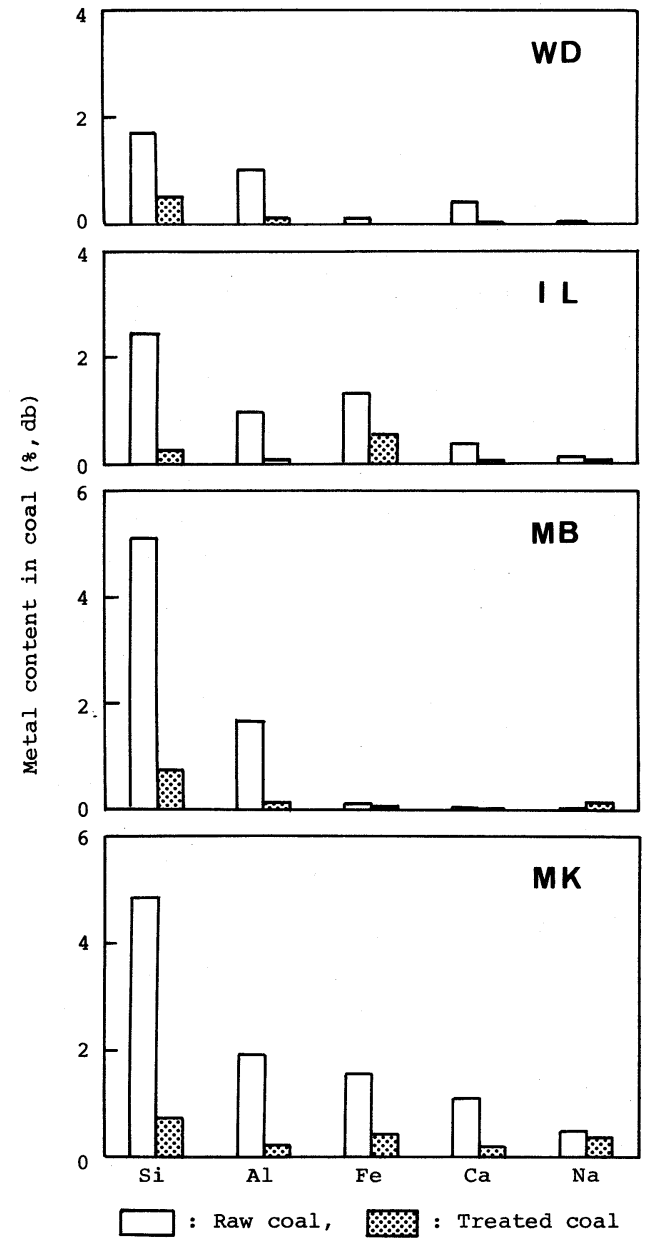

Fig. 1 Reduction of metal content upon alkali treatment

石炭の化学的処理に際して，個々の鉱物質がどのよ らに変化するかについて詳しく検討した研究は 2 ,
3 の例 10116)17)を除いてほとんどない。ここでは， $\mathrm{NaOH}$ 処理前後の鉱物質の形態変化を可能な限り明ら かにすることを試みた。はじめに, 石炭に含まれる各 元素量を原子吸光法で求めた。結果の一例をFig. 1に 棒グラフで示す。いずれの石炭の場合も, 脱灰率が 80 $\%$ 程度の試料の含有元素量を表示してある。元素の種 類によって除去される程度が異なること, その除去率 が石炭によって異なること, さらには処理炭中に残存 する元素の量と比率などがわかる。除去の割合を各元 素, 各石炭について算出すると, $\mathrm{Si}$ の除去率は, WD, 68；IL，89；MB，84；MK，85\%であり，ほぼ脱灰率 と見合った量が除去されているといえよう。同様に Alの除去率も, WD, 87; IL, 96; MB, 89; MK, 87\% である。これらの主要元素以外のものでは石炭中の鉱 物質の量や種類による除去率の差が認められた。すな わち, Fe除去率では, WD, 87; IL, 55; MB, 26; MK, 73\%であり，Ca除去率では，WD, 95；IL, 97; MB， 42; MK, 79\%であった。同じFe分であっても, IL炭 中のものは浸出されにくく, MB炭中の少量のFe成分 も非常に除去されにくいことがわかる。同様に, MB 炭中に含まれるCa分も絶対量は少ないのであるが, 浸 出除去が困難である。 $\mathrm{Na}$ 分については, $\mathrm{NaOH}$ 処理時 の残留分の完全除去が困難であるため, 場合によって は処理前の含有量より増えることさえあり,この脱灰 法のひとつの問題点である。

前報および以下の 3.3 に示す高温灰の X 線回折の結 果を参考にすると，各金属はTable 2に示すような酸 化物あるいは硫酸塩の形態をとると考えられる。上で 求められた元素組成から，高温灰の成分を推定すると， 表に示すような結果になり，重量の合計がほぼ100\% になる。このことから，これらの石炭に含まれる元素 の種類としてこの 7 種を考えれば十分であること, 原 子吸光法で求めた元素分析の精度が良いこと，これら 
Table 4 Distribution of elements in each step ${ }^{a}$

\begin{tabular}{lrrrrr}
\hline \multicolumn{1}{c}{ Treatment step } & $\mathrm{Si}$ & $\mathrm{Al}$ & $\mathrm{Fe}$ & $\mathrm{Ca}$ & $\mathrm{Mg}$ \\
\hline Raw-coal & 255 & 85 & 7.0 & 4.5 & 3.5 \\
NaOH-treatment & 156 & 13 & 0.2 & 0 & 0 \\
HCl-treatment & 59 & 65 & 4.5 & 0.6 & 0.6 \\
Water washing & 3 & 0 & 0.1 & 0.9 & 0.2 \\
Treated coal & 41 & 7 & 2.1 & 3.0 & 2.7 \\
\hline
\end{tabular}

${ }^{\mathrm{a}}$ The amount of element is represented in $\mathrm{mg}, 5 \mathrm{~g}$ of $\mathrm{MB}$ raw coal being used.

の化合物の形態の仮定が妥当であること，などがわか る。

上に述べた各元素の除去率はすべて水による洗浄操 作後の最終的な数字であるが，脱灰プロセスを考える 際には，各処理段階での各元素の除去割合を知ること が重要である。そこで, MB炭の場合について, $\mathrm{NaOH}$ 処理, $\mathrm{HCl}$ 洗浄, イオン交換水洗浄の各段階お よび処理炭に各元素がどのよらに分配されるかを詳し く検討した。結果をTable 4に示す。 $5 \mathrm{~g}$ の石炭を 250 $\mathrm{m} \ell$ のaOH溶液で処理し, $250 \mathrm{~m} \ell$ のCl溶液で酸洗浄し たのち, 各 $500 \mathrm{~m} \ell$ の水で 5 回水洗し処理炭を得た。 5 回 の水洗液に含まれた金属量を加えてTable 4 に示して

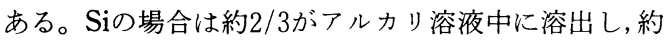
$1 / 3$ が酸溶液中に溶出する。多くはナトリウムけい酸 塩の形になるが，そのうちのあるものは酸にのみ溶解 するため,このよらな挙動を示すものと思われる。か なりの部分が処理炭中に残存するが，これはこのSiが 必ずしもアルカリ不溶, 酸不溶であることを意味して いるのではなく，むしろ未反応と考えるほらが妥当と 思われる。前報に示したように，Siの除去率が灰分の 除去率にほぼ比例して減少するからである。一方，

$\mathrm{Al}, \mathrm{Fe}, \mathrm{Ca}, \mathrm{Mg}$ などはむしろ酸の方に主として溶け 出している。このことが，アルカリ処理による脱灰に 酸洗浄が不可欠である理由である。用いる酸の種類に ついては, $\mathrm{Chi}{ }^{18)}$ が検討しており，酸によって一長 一短があるものの, 硫酸が最適であると結論している。 Caについては，もともとの含有量が少ないので, 立 入った議論をするべきではないが, Table 4によれば, かなりの部分が水洗時に除去されることがわかる。 Naについても同様に酸洗浄のみでは完全に除去でき ず，ある程度の Na分が水洗過程および処理炭中に残 っている。本法のようなアルカリ処理脱灰法において は, 水洗をいかに効率よく行らかが非常に重要である ことを示している。

\section{3 灰分中の化合物の形態}

処理前後のIL炭，MK炭をそれぞれ低温灰化，高温 灰化したもののX線解析結果をTable 5に示す。回折 強度の大小についても定性的に表示した。前報で示し たMB，WD炭の場合と同様に低温灰中にはQuartz, Kaolinite，Calciteなどが主として認められ，高温灰 中にはQuartz, Anhydriteが認められる。Fe分が多い IL, MK両石炭にはこれらのほか, 低温灰にPyrite, 高温灰にHematiteがかなりの濃度で存在している。 これらのPyrite分は後で示すよらにかなりの程度除去 されるのであるが，SiやAl成分に比べれば除去率が低 いため, 処理後の低温灰の主成分はPyriteとなり,高温 灰の主成分はHematite となるのである。 $\mathrm{MK}$ 炭のCa 分はFig.1からわかるように，かなり除去が困難であ る。X線的に観測されるのは，低温灰でCalcite，高 温灰でAnhydriteである。Ca分の除去が困難であるこ とは,MB炭の場合でも見られたが，Calcite酸に可 溶であり予想しない結果であった。石炭中では他の形 態であったものが，灰化の際に生成する $\mathrm{CO}_{2}$ にって Calciteになった可能性も考えられる。Ca分に関する このよらな挙動についてはこれまで詳しく吟味された ことがない。Albite $\left(\mathrm{NaAlSi}_{3} \mathrm{O}_{8}\right)$ と思われるものの存 在が両石炭ともに認められる。確定はできないが，長 石類の一種であることは確かであろう。MK炭の高温 灰にはNoselite $\left(\mathrm{Na}_{8} \mathrm{Al}_{6}\left(\mathrm{SiO}_{4}\right)_{6} \mathrm{SO}_{4}\right)$ がかなり残存する ことは, Fig. 1, Table 2に示した結果と一致する。こ の化合物はアルカリ処理によって生じたものでなく, アルカリ処理の際に残存したNa分が灰化過程で変質 して生成したものである。この事実はNa分の除去に 関して非常に重要であるにもかかわらず，これまでほ とんど考慮されていない。これは，脱灰よりも脱硫に 研究の重点が置かれていたためであろう。このように， $\mathrm{X}$ 線回折の結果をTable 2 に示すよらな元素組成の結 果とあわせ考えると, 溶解しにくい成分の同定なども 可能になるので, きわめて有力な情報源となる。ごく 最近報告された, Yangら ${ }^{17)}$ の電極炭素製造のための 
Table 5 Chemical species in ash

\begin{tabular}{|c|c|c|c|c|c|}
\hline \multirow{2}{*}{$\frac{\text { Coal }}{\text { IL }}$} & \multirow{2}{*}{$\frac{\text { Ash }}{\text { LTA }}$} & \multicolumn{2}{|c|}{ Ash from $\mathrm{RC}^{\mathrm{a}}$} & \multicolumn{2}{|c|}{ Ash from $\mathrm{TC}^{\mathbf{a}}$} \\
\hline & & Quartz & $(\mathrm{vs})^{\mathrm{b}}$ & Pyrite & $(v s)^{b}$ \\
\hline & & Calcite & (s) & $?^{\mathrm{c}}$ & $(\mathrm{s})$ \\
\hline & & Pyrite & (s) & Quartz & $(w)$ \\
\hline & & Kaolinite & $(\mathrm{m})$ & & \\
\hline & & Bassanite & $(w)$ & & \\
\hline & & Albite? & $(w)$ & & \\
\hline & HTA & Quartz & (vs) & Hematite & (vs) \\
\hline & & Hematite & (s) & Quartz & $(w)$ \\
\hline & & Anhydrite & $(\mathrm{w})$ & & \\
\hline \multirow[t]{12}{*}{ MK } & LTA & Quartz & (vs) & Quartz & (vs) \\
\hline & & Albite? & (s) & Pyrite & (vs) \\
\hline & & Calcite & (s) & Albite? & (s) \\
\hline & & Pyrite & $(\mathrm{s})$ & Calcite & $(\mathrm{s})$ \\
\hline & & Bassanite & $(\mathrm{m})$ & Bassanite & (s) \\
\hline & & Kaolinite & $(\mathrm{m})$ & $?^{d}$ & $(\mathrm{~m})$ \\
\hline & & Dolomite? & (w) & & \\
\hline & HTA & Quartz & (vs) & Hematite & (s) \\
\hline & & Anhydrite & $(\mathrm{s})$ & Quartz & (s) \\
\hline & & Albite? & $(\mathrm{s})$ & Anhydrite & (s) \\
\hline & & Hematite & (s) & Albite? & (s) \\
\hline & & & & Noselite & $(\mathrm{m})$ \\
\hline
\end{tabular}

${ }^{a}$ RC, Raw coal ; TC, Treated coal

${ }^{\text {b }}$ vs, very strong; s, strong; m, medium; w, weak

c d spacing, 2.22, $1.76 \AA$

d d spacing, 2.21, $1.85 \AA$

Table 6 Sulfur content in raw and treated coals

\begin{tabular}{|c|c|c|c|c|c|c|}
\hline \multirow{3}{*}{ Coal } & \multicolumn{3}{|c|}{ Total sulfur } & \multicolumn{3}{|c|}{ Pyritic sulfur } \\
\hline & \multicolumn{2}{|c|}{ Content $(\%, \mathrm{db})$} & \multirow{2}{*}{$\begin{array}{c}\text { Removal } \\
(\%)\end{array}$} & \multicolumn{2}{|c|}{ Content $(\%, \mathrm{db})$} & \multirow{2}{*}{$\begin{array}{c}\text { Removal } \\
(\%)\end{array}$} \\
\hline & $\mathrm{RC}$ & $\mathrm{TC}^{\mathrm{a}}$ & & $\mathrm{RC}$ & $\mathrm{TC}^{\mathrm{a}}$ & \\
\hline IL & 3.2 & 2.5 & 23 & 0.93 & 0.58 & 37 \\
\hline MK & 2.9 & 1. 7 & 40 & 1. 3 & 0.15 & 88 \\
\hline
\end{tabular}

${ }^{\mathrm{a}}$ Ash reduction on treatment was around $80 \%$ for both coals.

脱灰研究においても同様の手法が用いられている。

\section{4 硫黄分の挙動}

前報では比較的硫黄含有量の少ないWD炭とMB炭 を用いてアルカリ処理を行ったが，いずれの場合も硫 黄除去率は低く，WD炭の場合ではせいぜい3\%， MB炭の場合でも $10 \%$ 程度であった 7 。その理由は Pyrite硫黄分がそれぞれ0.05，0.03\%と少なく， ほと んどがアルカリ処理では除去しにくい有機硫黄である
ためであった。本報告においては，Pyriteを比較的多 く含むIL炭，MK炭を用いて，灰分除去とともに硫黄 分除去の様子を検討したのでその結果をTable 6に示 す。予想通り, これらの石炭からの硫黄除去率は高く, それぞれ $23 \% ， 40 \%$ となった。Pyrite型硫黄の除去率 は両石炭でかなり異なり, MK炭では $88 \%$ に達するも のの, IL炭では37\%にとどまった。両処理炭中に Pyriteが残存していることはX線回折でも確認されて 
いる。この両者の差の原因は現在のとこ ろ不明であるが, Pyriteの形態によって 反応性が異なることも可能性としては考 えられる。

Pyrite硫黄以外の硫黄を有機硫黄と考 えると, その除去率は, IL, MK炭でそ れぞれ $15 \% ， 3 \%$ まった。このような 処理条件では有機硫黄の除去が不十分で あることは，これまでの結果からも予測 できることである。

\section{5 石炭の発熱量の変化}

Table 7 に処理前後の総発熱量の值を示す。原炭

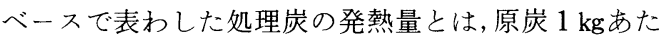
り含有されていた熱量のらち処理炭に残存している熱 量を示すものであり，処理炭の収率をもとに算出した ものである。WD，MB炭で認められたのと同様に， 処理炭の発熱量は増加し, IL, MK炭の発熱量は29.3, $27.9 \mathrm{MJ} / \mathrm{kg}$ のものが，処理後にはそれぞれ32.5,33.9 $\mathrm{MJ} / \mathrm{kg}$ となった。原炭べースでみると熱量の損失は 5 \%程度であった。損失分は，アルカリ溶液に溶出した 有機質が約 $2 \%$ で，あとは実験操作上の機械的損失に よるものである。後者については若干改善の余地はあ ろら。

この結果を，これまでに報告されているデータと比 ベてみる。正確なマスバランスが掲載されていない論 文が多いので，比較できない場合もあるが，IL炭に 対する石炭可燃分あるいは熱量の回収率のデータが示 されているものを挙げると, $\mathrm{Na}_{2} \mathrm{CO}_{3} / \mathrm{O}_{2}$ 法13)- $88 \%$, $\mathrm{Na}_{2} \mathrm{CO}_{3} / \mathrm{O}_{2}+\mathrm{Na}_{2} \mathrm{CO}_{3} / \mathrm{N}_{2}$ の 2 段法 ${ }^{12)}-91 \%$, $\mathrm{NaOH} / \mathrm{KOH}$ 溶融塩法 ${ }^{14)}-76 \%, \mathrm{NH}_{3} / \mathrm{O}_{2}$ 法 $^{19)}-87 \%$ の ような值が報告されている。一般的にいって，10\%あ るいはそれ以上の損失が見られるのに対してTable 7 の結果では94\%であった。脱灰率も，溶融塩法を除け ば, 本方法より劣るので, 本研究の結果は比較的良好 と言えよう。

\section{4. 結 言}

アルカリ処理による石炭の脱灰，脱硫を行い，反応 性を支配する諸因子について検討した。石炭のもつ熱 量の損失を最小限に押えて，脱灰することができたが， 脱灰率は石炭にもともと存在していた灰分の種類およ び量に依存した。灰分含有量の多い石炭の脱灰率を上 げるには，より厳しい条件が必要である。脱硫に関し ては, Pyrite型硫黄分の除去は比較的容易であり，石 炭によっては，ほぼ定量的に除去しらるが，全硫黄分 の除去率は50\%に達しなかった。X線回折法と原子吸
光法を組み合わせることにより，除去されにくい鉱物 質の同定を行い, $\mathrm{Ca}$ 分や $\mathrm{Na}$ 分の除去がかなり問題に なることを明らかにした。

(謝辞)

本研究は電源開発(株)の援助のもとに行った。記し て謝意を表する。

\section{文献}

1）後藤典弘, 燃協誌, 62, 378 (1983)

2）富田 彰，玉井康勝，燃協誌，61，405（1982）

3）村田逞詮，燃協誌，59，803（1980)

4) Wheelock, T. D. (Ed), "Coal Desulfurization", Am. Chem. Soc., Washington, D. C. (1977)

5) Tsai, S. C., "Fundamentals of Coal Beneficiation and Utilization”, Elsevier, Amsterdam (1982)

6) Morrison, G. F., "Chemical Desulfurization of Coal”, IEA Coal Research, London (1981)

7) Wang, Z. -Y., Ohtsuka, Y. and Tomita, A., Fuel Process. Technol., 13, 279 (1986)

8) Gladfelter, W. L. and Dickerhoof, D. W., Fuel, 55, 355 (1976)

9) Reggel, L., Raymond, R., Wender, I. and Blaustein, B. D., Prepr., Am. Chem., Soc., Div. Fuel Chem., 17, ( 1 ), 44 (1972)

10) Waugh, A. B. and Bowling, K. McG., Fuel Process. Technol., 9, 217 (1984)

11) Stambaugh, E. P., et al., Prepr., 2nd Annual Symp. on Coal Gasification, Liquefaction and Utilization, Pittsburgh (1975)

12) Fan, C. -W., Markuszewski, R. and Wheelock, T. D., Prepr., Am. Chem., Soc., Div. Fuel chem., 29, (1), 114 (1984)

13) Chuang, K. C., Markuszewski, R. and Wheelock, T. D., Fuel Process. Technol., 7 , 43 (1983)

14) Masciantonio, P. X., Fuel, 44, 269 (1965)

15) Meyers, R. A., Hart, W. D. and McClanathan, L. C., Coal Process. Technol., 7, 89 (1981) 
16) Fan, C. -W., Markuszewski, R. and Wheelock, T. D., Prepr., Am. Chem., Soc., Div. Fuel Chem., 29, (4), 319 (1984)

17) Yang, R. T., Das, S. K. and Tsai, B. M., Fuel, 64, 735 (1985)

18) Chi, C. -Y., Markuszewski, R. and Wheelock,
T. D., Prepr., Am. Chem., Soc., Div. Fuel Chem., 30, (2), 49 (1985)

19) Sareen, S. S., "Coal Desulfurization" (Ed. Wheelock), Am. Chem. Soc., Washington, D. C., p. 173 (1977)

\title{
A Study on the Removal of Mineral Matter from Coal by Alkali Treatment
}

\author{
Yasuo OHTSUKA, Zheng-Yu WANG and Akira ToMITA \\ (Chemical Research Institute of Non-Aqueous Solutions,Tohoku University)
}

\begin{abstract}
SYNOPSIS:- The removal of mineral matter from four coals was attempted by using caustic digestion followed by acid washing. A mild treatment at $460 \mathrm{~K}$ was found enough to remove most minerals without losing heating value of coal. X-ray diffraction measurements of low temperature-and high temperature-ashes of both raw and treated coals revealed the chemical form of minerals which were difficult to be removed. The reduction of $\mathrm{Si}$ and $\mathrm{Al}$ content was proportional to the ash reduction, but the removal of $\mathrm{Fe}$ and $\mathrm{Ca}$ components strongly depended on the type of minerals. The degree of desulfurization was also determined. It was found that pyritic sulfur was easily removed but other type of sulfur seemed to be almost unaffected by the present treatment.
\end{abstract}

Key Words

Alkali treatment, Coal, Demineralization, Desulfurization 